\title{
Report
}

\section{Digital Tools and the Right to Know}

\author{
Andrea Rolke, Hans-Karl Rath and Jan Backmann*
}

In very near future, there will be a significant increase in the number of opportunities open to consumers and public and private corporations to base their purchase decisions on much more than price and performance characteristics. Still largely unnoticed by the majority of the public, a revolutionary change for the better is currently taking place as regards the availability of sustainability-related information on sales products. Consumers will be able to obtain all kinds of information on aspects they care about, even beyond sustainability.

This report examines the driving forces behind this development and the technological basis, and how these developments are taking place in different industrial sectors. We also show that this process is embedded in a much broader development, which will result in the progressive digitalisation of contractual obligations and compliance with regulatory and societal requirements.

\section{Introduction}

When we buy a product, an increasing number of us want to know what it is made of, who made it and where it comes from. This information is readily available if you buy potatoes from the farm at the roadside during a country outing. However, most of the products we buy are produced under less idyllic circumstances and consist of many parts originating from all over the world.

Furthermore, our demands are growing ever more specific and individual: depending on our preferences, we want products to be, for instance, fair, organic, free of certain substances, vegetarian, vegan, kosher, halal, of a particular geographic origin or harvested in a specific way. In short, the buyer wants to know more about the product.

Bowing to public pressure, regulators around the globe are creating ever more stringent legal requirements for products on the market - with very differ- ent objectives, including ecological, political, social and protectionist. For instance, the European Union made it a requirement for suppliers to inform professional users, customers and recyclers about the presence of what are referred to as 'substances of very high concern (SVHC).'

Moreover, governmental institutions, public and private corporations, retail chains and communities are establishing green procurement policies. ${ }^{23}$ In order to win such a tender, one must be able to supply and document as many details as possible about the products offered and the associated supply chains as quickly as possible. The ability to comply efficiently with the diverse requirements can decide whether it is worth serving a market.In addition, the transparency and information transfer helps in the fight against counterfeiting.

To meet all these societal, regulatory and consumer requirements, information has to be transferred along the supply chain - from the very beginning to the final customer or even the recycler. In the present paper, we show how this can be accomplished and where this development will lead.

Taking a closer look at these new developments, this paper will describe a significant step forward to-

DOI: 10.21552/delphi/2019/3/8

* Andrea Rolke is a Chemical Legislation Expert at F.Hoffmann-La Roche Ltd, Basel, Switzerland; Dr Hans-Karl Rath is Vice President of Operations at iPoint-systems $\mathrm{GmbH}$, Reutlingen, Germany; Jan Backmann is Head Chemical Legislation at F.Hoffmann-La Roche Ltd, Basel, Switzerland. For Correspondence: <jan.backmann@roche.com>

1 The official list of SVHC: <https://echa.europa.eu/en/candidate -list-table> accessed 2 September 2019

2 Healthcare Without Harm, 'Sustainable Procurement: The (Un)Expected Strategy to Achieve Healthier Environments in Healthcare' $<$ https://noharm-europe.org/articles/news/europe/sustainable -procurement-unexpected-strategy-achieve-healthier -environments> accessed 2 September 2019

3 The National Agency for Public Procurement, <https://www upphandlingsmyndigheten.se/en/sustainable-public -procurement/sustainable-procurement-criteria/nursing-and-care/ health-care-eee/> accessed 2 September 2019 
wards an easier access to product information. Currently, entire supply chains are being given the tools to channel all the necessary information to convince consumers or professional users that whatever concerns they have about a product are taken care of, and authorities can check whether the legal requirements are complied with. In fact, when laws grow ever more complex and are enforced via computer routines, the time has come to talk about the digitalisation ${ }^{4}$ of compliance, legal enforcement and legal affairs.

\section{How it All Began}

In the 1970 and 80 , there were a number of environmental disasters involving chemicals, such as the Flixborough disaster in England (1974), the Seveso disaster in Italy (1976) and the Bhopal disaster in India (1984). As a consequence, legislation was introduced to protect the environment from the impact of hazardous substances. Originally focusing on the production of chemicals, material compliance for other products was soon also considered from a legal perspective.

One of the main drivers was the requirements resulting from the EU's 'End of Life Vehicles Directive' (ELV). In 1997, to tackle the issue of 8 to 9 million tonnes of waste from automotive products in the European Union every year, the EU adopted a proposal for a directive, which eventually came into effect as ELV-Directive 2000/53/EC. To fulfil the obligations for several reporting requirements, the automotive industry set up the International Material Data System (IMDS), a global data repository that contains information on materials and substances present in automobiles. The data are collected, maintained, analysed and archived throughout the entire supply chain at vehicle manufacturers.

4 The two terms digitisation and digitalisation are often used as synonyms. However, strictly speaking, there is an important difference. Digitisation means the conversion of analogue source material into a numerical format. Digitalisation is the use of digital technologies to obtain new insights. Therefore, we use here and hereinafter the latter term

5 Regulation (EC) No 1907/2006 on Registration, Evaluation, Authorisation and Restriction of Chemicals

6 See, <https://www.askreach.eu/> accessed 2 September 2019

7 Restriction of Hazardous Substances Directive, Directive 2011/65/EU, 3 January 2013

8 Directive (EU) 2018/851
Environmental compliance has become a moving target since then - each region can impose unique environmental requirements on products sold in their market and new regulations continue to emerge. Different global substance regulations pose significant challenges for all actors. If we look at product regulations directly restricting and limiting substances, we find more than 750 laws on a global scale today. Another 140 are already in the legislative process in different countries.

\section{What is Driving the Developments?}

\section{Regulatory Drivers}

The 'right to know' found its legislative expression through Article 33 of the European REACH ${ }^{5}$ regulation. This important article stipulates that a supplier has to inform a professional recipient automatically and any customer on request whether a product contains a critical substance. To help European consumers exercise their right to know, the LIFE AskREACH ${ }^{6}$ project was initiated. The EU-funded project aims to educate the public, trade and industry regarding unwelcome substances in everyday objects. The core of the project is a smartphone app, which informs consumers about such substances and sends queries to suppliers.

In the electrical and electronic merchandise sector, the $\mathrm{RoHS}^{7}$ directive restricts the use of hazardous substances. The particular challenge of this law is related to the high complexity of the electronic devices that consist of countless, very different, sometimes very small components, which must not contain the banned substances. The directive is very effective as the presence of banned substances does not just carry the obligation to inform the recipient, but prohibits the device from being marketed.

The Revised European Waste Framework Directive $(\mathrm{WFD})^{8}$ Article $9(2)$ requires:

- the establishment and maintenance of a database for information on substances in articles down the supply chain

- the provision of access to the database for waste treatment operators and consumers (upon request).

This will force all suppliers to enter the necessary information in a database, which is being created by the European Chemical Agency. 
On the other side of the Atlantic, the Dodd-Frank Wall Street Reform and Consumer Protection Act, better known as the Conflict Minerals Regulation, requires companies using certain minerals from a number of African countries in their products to disclose the source of these minerals, ${ }^{9}$ while the California Proposition $65^{10}$ is a law designed to reduce or eliminate exposure to chemicals which can cause cancer or birth defects, such as in consumer products, by issuing warnings in advance.

Internationally, the Stockholm Convention on Persistent Organic Pollutants aims to eliminate or restrict the production and use of persistent organic pollutants (POPs) ${ }^{11}$ and the Hong Kong International Convention for the safe and environmentally sound recycling of ships ensures that at the end of their operating live ships will be recycled with a minimal adverse effects on human health and the environment. ${ }^{12}$

\section{Non-Governmental Drivers}

The SIN List, ${ }^{13}$ which is a compilation of substances that, according to the opinion of the NGO ChemSec, are undesirable and need to be substituted. In addition there are diverse company lists (eg the Siemens List of Declarable Substances, LoDS), standards from Bosch N $2580^{14}$ or Daimler DBL $858^{15}$ and industry associations (eg the Global Automotive Declarable Substance List, GADSL), Railway Industry Substance List (RISL) ${ }^{16}$, or cross-sector initiatives (see below IV.6)

For instance, in the textile industry several standards have been developed:

- The Zero Discharge of Hazardous Chemicals (ZDHC) $\mathrm{MRSL}^{17}$ is a list of chemical substances banned from intentional use in facilities that process textile materials and trim parts in apparel and footwear.

- Apparel \& Footwear International RSL Management Working Group (AFIRM) ${ }^{18}$ issues restricted substances lists for industry's products and packaging.

Elsewhere, the BASTA database for building and construction materials comprises products that do not contain undesirable substances ${ }^{19}$ and the Japan Automobile Manufacturers Association, Inc. (JAMA) and the Japan Auto Parts Industries Association (JAPIA) provide a JAMA/JAPIA Standard Material
Datasheet. $^{20}$ This standard investigation sheet is intended to collect information on materials and substances used in vehicle parts to meet both domestic and international environmental rules.

\section{Voluntary Public Schemes}

The EU's Green Public Procurement $(G P P)^{21}$ is one example of a voluntary public scheme. GPP is a voluntary instrument to promote a more resource-efficient economy in the EU. It is intended to stimulate the demand for more sustainable goods and services.

\section{Religious Rules}

In this category, examples include $\operatorname{kosher}^{22}$ and ha$\mathrm{lal}^{23}$. In order to be reliably able to document that in

9 Dodd-Frank Wall Street Reform and Consumer Protection Act, Section 1502; 22 August 2012, the US Securities and Exchange Commission adopted Rule 13p-1 under the Exchange Act, which is known as the 'Conflict Minerals Rule'

10 The Safe Drinking Water and Toxic Enforcement Act of 1986

11 Stockholm Convention on Persistent Organic Pollutants is an international environmental treaty, signed in 2001 and effective since May 2004

12 The Hong Kong International Convention for the Safe and Environmentally Sound Recycling of Ships, 2009

13 See <https://chemsec.org/business-tool/sin-list/> accessed 2 September 2019

14 See <http://purchasing.bosch.com/en/de/info/download/ downloads.html> accessed 2 September 2019

15 See <https://daimler.portal.covisint.com/web/portal/ veroeffentlichung_dbl> accessed 2 September 2019

16 The Railway Industry Substance List provides a comprehensive and accurate list of the prohibited and declarable chemicals used specifically by the railway industry. First initiated as a result of the European REACH regulation (EC 1907/2006), the list will help users to comply with the regulation's legal provisions for manufacturers, downstream users, and importers of substances. Furthermore, the UNIFE Topical Group has extended the legal scope outside Europe to include Canada, China and the USA

17 See <https://www.chem-map.com/zdhc-mrsl/> accessed 2 September 2019

18 See <https://www.afirm-group.com/> accessed 2 September 2019

19 See <https://www.bastaonline.se/about-basta/about-basta/?lang $=$ en $>$ accessed 2 September 2019

20 See <https://www.japia.or.jp/work/kankyou/datasheet/> accessed 2 September 2019

21 European Commission, 'Green Public Procurement' <http://ec .europa.eu/environment/gpp > accessed 2 September 2019

22 Kashrut is a set of Jewish religious dietary laws. Food that may be consumed according to Jewish law is deemed kosher

23 The term halal is particularly associated with Islamic dietary customs 
the manufacturing these rules were observed, the same digital tools can be used.

\section{How Do the Different Industries Cope with the Pressure?}

Due to different boundary conditions, in different regulatory environments, and to the different nature of the manufactured products, various sectors have developed different coping strategies and tools. Before discussing the necessity to harmonize the various approaches, we would like to describe the situations in some of the sectors.

\section{Automotive}

In the automotive sector, a well-established data exchange platform exists. This exchange platform offers the advantages that all data covering restricted substances within this sector are collected centrally via a common interface, ensuring data consistency and some validation. The platform in question is the 'International Material Data System' (IMDS), established in 2001. In recent years, a similar platform was created for the Chinese market, the 'China Automotive Material Data System' (CAMDS).

Exchanging full material disclosure data is a must on these platforms. Unless the data are not provided, the 'Production Part Approval Process' (PPAP) used in the automotive supply chain is not complete and the products or parts may not be used by a supplier. Some parts are only available through distributors, who rarely have the data necessary to update IMDS/CAMDS at their disposal and often cannot afford to do so. Furthermore, data collection teams and software need to establish a connection with the manufacturer either directly or through the distributor. Some components or systems, such as entertainment systems linked to mobile phones, may require specialist testing/licensing based on the country of sale. This is rarely captured at the same time as the product compliance data.

24 MedTech Europe, 'Guidance on Material Declaration' <https:// www.medtecheurope.org> accessed 2 September 2019

\section{Electronics}

There is no comparable data exchange platform like the IMDS established in this sector.

The global trade association IPC, a member-driven organisation, provides material declaration data exchange standards covering the entire electronics industry supply chain. The IPC-175x family of standards establishes a standard reporting format for data exchange between supply chain participants. Another new international standard, IEC 62474, is about to be established along the lines of the IPC standard.

Although most legislation restricting the use of certain substances does not require the transfer or declaration of data in a standard format, a product must comply with certain rules or it will be taken off the market (such as EU RoHS, for example).

Compliance may also be linked to product safety (EU RoHS is a CE marking directive), which requires additional testing. Providing a full material declaration (FMD) is not the standard case within this sector, although the demand is increasing. In the electronics sector, it is common practice to provide partial material declarations (ie declare only the regulated substances in the product), negative declarations (declare the absence of regulated substances), or certificates of compliance ( $\mathrm{CoC})$, which state only the compliance with certain regulations. As a consequence, every regulatory update or change leads to increased activities within the supply chain to gather new data.

Some parts are only available through distributors, who can usually supply only limited information on compliance data; other legislation varies depending on the distributor. Data collection teams and software need to establish connections with the manufacturer either directly or through the distributor.

The method of declaring restricted or banned substances varies depending on the legislation. Compliance with some legislation involves more than merely collecting the substance data, such as CA Prop 65, which requires an exposure analysis and testing against substance limits that vary by substance.

\section{Medical technology}

In January 2019, the European medical technology association MedTech Europe published a guide on material declaration. ${ }^{24}$ It is meant to provide guid- 
ance for medical technology manufacturers on communicating a common message on the background and importance of providing material declarations along the supply chain. With these documents, an entire key industry sector is striving for a complete chemical composition of any product.

Digital technologies cannot just help to cover the need to comply with substance-related legislation and green procurement. There is also a need to combat the counterfeiting of reagents. ${ }^{25}$ Not only does such counterfeiting deprive innovative companies of their legitimate profits or damage their reputation, it can also result in life-threatening misdiagnoses. In addition, public research funds are wasted on potentially useless experiments.

\section{Pharma}

For many years, the pharmaceutical industry has been required to carefully document its manufacturing and supply chain under the Good Manufacturing Practice (GMP) regulation. These requirements are increasingly being met by means of electronic data processing, including Electronic Batch Record (EBR).

A serious problem is that criminals attempt to counterfeit novel, patent-protected, life-saving drugs, most of them expensive and thus promising high profits for forgers. Thus, the electronic transfer of information in the supply chain can make a significant contribution towards protecting the health and lives of patients with life-threatening diseases. ${ }^{26} \mathrm{~A}$ multinational software corporation provides a blockchain application designed to ensure that all drugs which hospitals and pharmacies return to pharmaceutical wholesalers are validated before resale. The blockchain was developed in a public cloud network of several large pharmaceutical wholesalers and manufacturers. ${ }^{27}$

Such a blockchain solution also helps pharmaceutical wholesalers comply with the new US Drug Supply Security Act (DSCSA), which enters into force in November 2019 and requires retailers to validate prescription drugs that are returned before resale. ${ }^{28}$

Increasingly, green procurement is also being used for pharmaceuticals. One key criterion is the emission of the active pharmaceutical ingredient at production sites, which often are located in countries that struggle with environmental pollution. Pharmaceutical companies are rightly expected to control and minimise emissions of hazardous substances along their supply chains, which need to be transparent.

We appreciate that large pharmaceutical companies are also discussing the establishment of standards for their supply chain to process more efficiently the information on substances found in packaging materials and devices used by patients. These will involve material declaration tools.

\section{Other Sectors}

The authors are aware of developments in other sectors which were not mentioned above and in which the authors are not so well versed. In these other sectors, there are at least lists of substances which companies want to avoid and/or request their suppliers to avoid: ${ }^{29}$

- Railway: UNIFE Railway Industry Substances List $(\text { RISL) })^{30}$

- Shipbuilding: Inventory of Hazardous Materials (IHM) for substances identified and listed by the Hong Kong Convention (2009) and EU Regulation $1257 / 2013$

- Aerospace and defence: Aerospace and Defence Declarable Substance List (AD-DSL) ${ }^{31}$

- Textiles: Manufacturing Restricted Substances List (MRSL)

The existence of such lists implies that there are established, appropriate documentation processes in the supply chain which call for rationalisation, automation and digitalisation.

25 Don Gunasekera 'Fight Fake Reagents with Digital Tools' (2017) Nature 546, 474

26 Tim K Mackey and Gaurvika Nayyar, 'A Review of Existing and Emerging Digital Technologies to Combat the Global Trade in Fake Medicines' (2017) 16 Expert Opinion on Drug Safety 5, 587-602

27 Jim O'Donnell, 'SAP Blockchain hilft bei Bekämpfung gefälschter Arzneimittel' <https://www.computerweekly.com/de/feature/SAP -Blockchain-hilft-bei-Bekaempfung-gefaelschter-Arzneimittel> accessed 2 September 2019

28 Jim O'Donnell, 'SAP Blockchain Service Helps Fight Counterfeit Drugs' <https://searchsap.techtarget.com/feature/SAP-blockchain -service-helps-fight-counterfeit-drugs> accessed 2 September 2019

29 Jean-Pierre Theret, 'Future of 'Substances and Materials in Products' Data Exchange Formats as Standards' 2019 Conference Proceedings of 2019 IPC Apex Expo Technical Conference

30 The European Rail Industry, 'The Railway Industry Substance List' $<$ http://www.unife.org/railway-industry-substance-list.html> accessed 2 September 2019

31 IAEG, 'Aerospace and Defence Declarable Substances List' <http://www.iaeg.com/chemicalrpt/addsl/> 


\section{Cross-Sector Collaboration on Material Declaration}

It has become clear that an alternative to sector-specific solutions needs to be found. Not only do the different sectors overlap, they are also part of cross-sector supply chains.

In 2018, the Proactive Alliance 'Substances in Articles' was founded in Europe. This body - without having a formal mandate - brings together representatives from the different sectors such as automotive, chemicals, childcare products, electrical and electronics, furniture, home textiles, mechanics, medical devices, metalworking and metal articles, textiles and sports equipment. The group is moderated by the Society for Institutional Analysis (SOFIA) at the University of Applied Science Darmstadt, Germany. It remains to be seen whether this body has sufficient penetrative power to trigger a sustainable drive for cross-sectoral collaboration and standardisation.

We also expect that the European Chemical Agency will drive the standardisation when implementing its database for substances in articles. The database will need to be used by all sectors and thus catalyse a cross-sectoral harmonisation.

We are also aware of a cross-sectoral initiative in Japan organised by the Japan Environmental Management Association for Industry (JEMAI) ${ }^{32}$, which formed the Joint Article Management Promotion consortium (JAMP) that hosts the chemSHERPA cross-sector tool for substance reporting in chemistry and articles. ${ }^{33}$

\section{Why it Makes Sense to have a Full Chemical Composition of any Product}

Many industry representatives will be aghast at hearing about the concept of a full material declaration which requires the complete chemical composition of their products to be made available to their customer (downstream user). Is it even possible or necessary? We think so. And we are even convinced that,

32 See, <http://www.jemai.or.jp/english> accessed 2 September

33 See, <https://chemsherpa.net/english> accessed 2 September

34 Mayank Pratap, 'How is Blockchain Disrupting the Supply Chain Industry?' <https://hackernoon.com/how-is-blockchain-disrupting -the-supply-chain-industry-f3a1c599daef> accessed 2 September in the long run, it is in the best interest of most players in the industry.

Firstly, let us consider the competing concept, which is a harmonised list of banned and reportable substances. This concept - which, at first glance, looks clear and simple - would require a supplier to report to a recipient in the supply chain whether a substance on the list is present or not (positive and negative declaration). However, the concept of a harmonised list of substances is, in fact, unrealistic because different national or international authorities (eg European Chemical Agency) or private companies will not stop extending their lists.

There are even legal mechanisms which lead to the regular extension of the lists, as in the case of REACH or EU RoHS. Although a full material declaration is not easy to achieve, it is clearly preferable to the harmonisation of lists. In order to reduce recurring queries for suppliers and thus irritation, cost and effort, it makes much more sense to make the effort once to obtain the full chemical composition and feed it into the data systems. When the legislation is revised, software can automatically check whether a newly regulated substance is present in a product without requesting this information every time the legislation is changed anywhere in the world. Thus, both the recipient subject to legislation and the supplier will benefit. With the full chemical composition available, it is also easier to measure the socio-economic effect of draft regulations restricting a specific substance. At the same time, it then helps the manufacturer to proactively redesign a product containing this substance.

\section{The Transfer of Information in Supply Chain and Blockchain Technology}

One increasingly important objective is the transparency of the supply chain to document the production process from the raw materials until the final product reaches the end-consumer. Further objectives for companies include the speeding up of supply chains, increasing sales and decreasing the amount of fraud in the flow of material and information. ${ }^{34}$

Supply chain transparency can be achieved by using blockchain technology, which uses immutable, encrypted transactions that are stored in databases which are distributed to a large number of computers linked to a common network via the internet. The distribution processes are automated and guarantee the timely distribution of the transferred informa- 
tion. Due to the decentralisation of transactions and systems, there is no single point of failure, which reduces the risk of data breaches.

For the supply chain, we see the following benefits: slow administrative processes containing manual paperwork can be replaced with real-time tracking and information-sharing possibilities. ${ }^{35}$ The history of the goods in the supply chain - from production to distribution - cannot only be shared with manufacturers, suppliers and vendors from all over the world, but also with authorities and even end-users. The immutability of the blockchain can create trust in the data and also help to fulfil regulatory compliance.

What are the biggest challenges when introducing blockchains in the supply chain industry?

Due to the high number of transactions and the numerous copies of these transactions all over the world, a huge number of datasets have to be stored. Further challenging questions are: What is the cost of implementation and data storage? How can we integrate legacy systems? Will this data be kept forever? Is it technically possible to implement a record management lifecycle process and what might it look like? How we can overcome the present absence of common standards? ${ }^{36}$

Trustworthy change management is needed: as the data in a blockchain is immutable, the correction of wrongly entered records means adding the correct information to the ledger containing the erroneous information and giving a plausible reason as to why a change is needed.

Furthermore, many companies will not accept the publication of proprietary details about their products and confidential business information. This would lead to the use of private permissioned blockchains with centrally granted access permissions.37 One additional drawback of blockchains is the high consumption of energy and computational power, at least when using public blockchains.

There are also alternatives to blockchains, such as central databases with well-maintained data that can be used by trusted parties and also allow real-time transactions. 37 Goods can already be marked with radio frequency identification (RFID) tags, barcodes or sensors and tracked today.

Time will tell whether the disadvantages of blockchains can be eliminated so that they gain acceptance and catch on as a standard in supply chain management - or whether other solutions might be found in the near future to increase transparency in the supply chain.

\section{Outlook}

Where is this all supposed to lead? From a consumer perspective: to a world in which we can buy products according to many more criteria than how much they cost, what they look like and whether they do what we want them to do. This is good news.

From the perspective of a manufacturer and trader: to a world which is more demanding and where it is not enough to make a product which is a fairly priced, attractive and has a decent quality. In this emerging world, the legitimate pursuit of profit will need to be better connected with social and environmental responsibility. The latter will increasingly not just be a question of voluntary commitment, but of legal compliance. ${ }^{37}$ This is good news - for those companies which are up to the challenge.

From a technology perspective, many changes are expected that will facilitate the implementation of the 'right to know'. Blockchains or their alternatives will play a central role, but also other technologies will have an important influence. Cloud solutions will offer an easier data exchange in some industrial sectors. To exchange huge data amounts, a standardisation of data exchange formats will be a prerequisite.

From the perspective of a professional working in the area of compliance, regulatory affairs, or sustainability, this development will lead to a completely changed occupational profile. Digitalisation will increasingly find its way into the field of compliance, of legal enforcement, and of legal affairs and transform and accelerate the hitherto established operation of law firms, legal departments and regulatory affairs experts ${ }^{38}$. This will make the life of the pro-

35 McKinsey and Company, 'Blockchain technology for supply chains-A must or a maybe?' <https://www.mckinsey.com/ business-functions/operations/our-insights/blockchain-technology -for-supply-chainsa-must-or-a-maybe $>$ accessed 2 September

36 Ashiq Anjum et al, 'Blockchain Standards for Compliance and Trust' < https://www.researchgate.net/publication/320364955 _Blockchain_Standards_for_Compliance_and_Trust $>$ accessed 2 September

37 Swiss Confederation, Botschaft zur Volksinitiative Für verantwortungsvolle Unternehmen - zum Schutz von Mensch und Umwelt, Federal Gazette/2017/6335

38 Jaap Bosman 'Uniform Legal Data Classification Will Reshape the Business of Law' <https://news.bloomberglaw.com/us-law-week/ insight-uniform-legal-data-classification-will-reshape-the-business -of-law> accessed 2 September 2019

39 Roy Strom, 'Big Law Business: The Algorithm Says You'll Win the Case. What Do You Say?' (2019) Bloomberg Environment Energy Report 
fessionals more interesting and potentially more gratifying as it can reduce routine tasks and leave more time for tricky questions. This is good news for any professional who is ready to embrace the challenges. 